\title{
Reinforcement corrosion in reinforced concrete Structures: Classification and overview
}

\author{
Nour Eldeen M. A. Abo Nassar \\ Civil Engineering Department, Near East University, Nicosia, Via Mersin 10, Turkey
}

\section{ARTICLE INFO}

\section{ARTICLE HISTORY}

Received: 12 January 2021

Revised: 19 January 2021

Accepted: 24 January 2021

Published: 31 January 2021

\section{KEYWORDS:}

Corrosion, reinforcement, concrete, carbonation, sulphate

\section{A B S T R AC T}

Reinforced concrete $(R C)$ structures have the ability to be extremely durable and able to withstand a diversity of different environmental cases. However, failure in these structures still happens due to precocious reinforcement erosion. If steel reinforcement corrodes in concrete structures, this leads to a decrease in the lifetime and durability of these structures, which cause early failure of the structures, costing significantly to inspect and maintain the deteriorating structures. Then, monitoring of reinforcement corrosion is of great importance to prevent early failure of structures. Structures corrosion can be decreased through correct monitoring and taking appropriate control measures in the appropriate period of time. When steel bars corrode, the formation of rust causes the concrete to be separated from the steel and then thereafter. In case this issue is not addressed, it may influence the entire structure. This paper attempts to present a comprehensive review of corrosion of rebar in RC structures, its mechanisms, monitoring and prevention.

\section{INTRODUCTION}

Steel corrosion is considered as one of the most common and related degradation processes experienced by $\mathrm{RC}$ structures. Corrosion of the steel leads to a decrease in the reinforcing area, and changes in the mechanical characteristics of the reinforcing bars (Fernandez et al., 2015), concrete cover cracks and splits and decrease the contact area between steel bars and the surrounding concrete. The most serious impact of corrosion of rebars is the alteration in the bond characteristics of steel and concrete (Alonso et al., 1998).

The concrete is reinforced with steel to support the structural element and make it stronger in the case of tension because concrete is known to be weak in tension, however, the structures fail due to the corrosion that occurs to the steel bars. Nowadays, steel corrosion has become a significant and widespread issue around the world, considering that the repair cost has been estimated at billions of dollars yearly. Added to this, the many intangible losses like the energy required to produce alternatives to corroded elements. Corrosion of steel in RC decreases its durability and may lead to structural failure (Quraishi et al., 2017).

Corrosion is a phenomenon that causes deterioration or damage to a material when subjected to various environmental conditions. Concrete corrosion includes an electrochemical process where each of the flow of electric currents and chemical reactions takes place. Because of the alkalinity of concrete $(\mathrm{pH}$ value usually ranges from 12 to 13), the steel in RC elements is in the passive case and thus is preserved through a thin film of oxide (Ormellese et al., 2006).

\section{CORROSION CLASSIFICATIONS}

According to Quraishi et al. (2011), Various types of corrosion could influence the metal in a variety of ways, that depend on its character and the precise ecological condition prevailing. A broad classification of the different corrosion forms is presented, and the 5 major categories are identified, as follows. 


\subsection{Uniform corrosion}

Uniform corrosion is an even attack toward the surface of a material and is the most popular kind of corrosion. It is also the milder one as the range of the attack can be judged comparatively readily, and the effect on material performance can be estimated fairly easily due to the ability to reproduce and examine the phenomenon constantly. In general, this kind of corrosion happens over comparatively large areas of the material's surface.

\subsection{Pitting corrosion}

It is an extremely localized attack which eventually leads to holes in the metal. It is one of the most destructive and virulent forms of erosion. Essentially, the alloys expose to pitting are those that depend on an oxide layer for protection, such as stainless steel.

\subsection{Galvanic corrosion}

In case two various metals are subjected to a corrosive environment, there will be an electric potential difference. If the two metals are electrically connected, the higher energetic metal will be the anode in the resulting galvanic cell and its corrosion will increase. An example of this corrosion cell is the utilization of steel screws to hold copper plates together.

\subsection{Crevice corrosion}

Crevice erosion is a localized attack that happens when cracks, which consist of crooked joints, or areas of partial shielding, are subjected to corrosive mediums. These resulting cells are indicated as focus cells. There are 2 popular cases, oxygen cells and metal ion cells.

\subsection{Selective dissolution}

It includes the selective dissolution of one of the components in a single-phase alloy or one of the phases in a multi-phase alloy, examples: dezincification, stratification and graphitization.

\section{CORROSION MECHANISM IN CONCRETE}

Concrete corrosion happens as a result of generating the electrochemical potential in the ways listed below:

- When there are two various metals in the RC structures, like steel rebar and aluminium tubes, or when there is a large difference in the characteristics of the surface of the steel bars, the creations of the compound cell can happen.
- Concentration cells can be created around the rebar because of the variations in the concentration of solvable ions, like alkalis and chlorides (see Fig. 1).

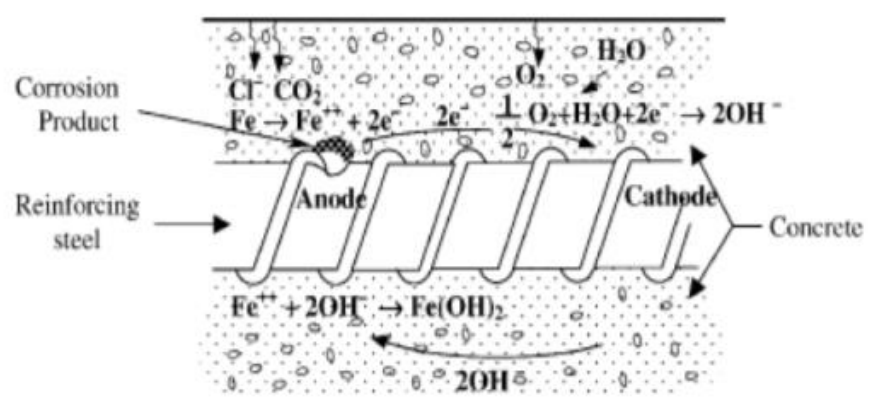

Fig. 1. Steel corrosion process in concrete (Neville, 2005)

Exposed steel will corrode in humid conditions due to differences in electrical potentials at the surface of the steel forming anode and cathode sites. The following reactions occur at the anode and the cathode (Qureshi et al., 2017).

Anode: $\mathrm{Fe} \rightarrow \mathrm{Fe}^{2}++2 \mathrm{e}^{-}$(Metallic iron)

Cathode: $1 \frac{1}{2} \mathrm{O} 2+\mathrm{H} 2 \mathrm{O}+2 \mathrm{e}^{-} \rightarrow 2 \mathrm{OH}^{-}$

Some parameters are necessary for corrosion to start. The existence of oxygen and moisture are two important factors that corrosion is not possible without. The rate of corrosion is slow if the water or oxygen amount is restricted. The existence of dampness and oxygen helps the corrosion to happen, leading to the formation of more $\mathrm{OH}^{-}$and thus the production of more rust component $\mathrm{Fe}(\mathrm{OH})^{-}$(Isgor \& Razaqpur, 2006).

\section{EFFECTS OF REINFORCEMENT CORROSION}

If the concrete is carbonated to the depth of the rebar and there is little moisture, the steel is probable to corrode. This degradation is often recognized through fine cracks parallel to the reinforcement direction along the structural element. Fortunately, since the corrosion is fairly homogeneous, cracking of the concrete cover in naturally reinforced or tightened solid components usually happens before the steel becomes too weak, giving an early visual warning of deterioration (Imam et al., 2018).

If the chlorides are intensified near the steel surface, and water and oxygen are abundant, intense pitting corrosion may happen. This decreases the cross-sectional area of the rods at these locations, whilst the remainder of the rod may be left un-corroded. Structural cracks, or honeycombs, can also make favourable conditions for erosion by allowing the local entry of aggressive agents. (Imam et al., 2018). 
The corrosion of the concrete reinforcement and spallation causes a lowering in the final capacitance and, more importantly, a decrease in the hardness and ductility of the reinforced concrete element mainly because of the weakness in the interfacial bond between the steel and concrete. The influences of steel bars corrosion on the behaviour of RC elements are presented in Fig. 2.

\begin{tabular}{|c|c|c|}
\hline \multicolumn{3}{|c|}{$\begin{array}{c}\text { EFFECTS OF REINFORCEMENT } \\
\text { CORROSION }\end{array}$} \\
\hline Effect on steel & $\begin{array}{l}\text { Effect on } \\
\text { concrete }\end{array}$ & $\begin{array}{l}\text { Effect on steel- } \\
\text { concrete bond }\end{array}$ \\
\hline $\begin{array}{l}\text { Loss in cross- } \\
\text { section and } \\
\text { reduction in } \\
\text { mechanical } \\
\text { strength }\end{array}$ & $\begin{array}{l}\text { Rust stains, } \\
\text { cracks, } \\
\text { delamination } \\
\text { and spalling }\end{array}$ & $\begin{array}{l}\text { disability in } \\
\text { transferring the } \\
\text { tensile strength } \\
\text { of steel to } \\
\text { concrete }\end{array}$ \\
\hline WEAK LO & $\begin{array}{l}\text { BEARING } \\
\text { ELEMEN }\end{array}$ & PACITY OF \\
\hline
\end{tabular}

Fig. 2. Impacts of reinforcement corrosion on reinforced concrete elements (Imam et al., 2018)

\section{CAUSES OF CORROSION}

\subsection{Carbonation}

The $\mathrm{CO}_{2}$ in the atmosphere interacts with the calcium, alkali hydroxides and cement phases, thereby reducing the $\mathrm{pH}$ value to the values close to neutral. The objective of this process is the depassivation of the steel from the carbonated areas. Carbonation is a diffusion process and thus, its depth is progressed by the exponential attenuation over time. The carbonization depth will not advance if the concrete is in wet or very dry condition (Sadeghi et al., 2019).

\subsection{Sulphate attack}

Sulphate aggression is a chemical reaction between sulfate ions from groundwater and hydrated cement products. Sulphate attack leads to the expansion of the cement paste in the concrete. The sulfate salt interacts with the existence of aluminates in the concrete in the form of calcium aluminate hydrate gel and produce calcium sulfate (ettringite) inside the hydrated cement paste. Because of this subsequent expansion in the hardened state, the concrete deteriorates. Cement includes some of the aluminas in the form of $\mathrm{C} 3 \mathrm{~A}$ and a small content in the form of $\mathrm{C} 4 \mathrm{AF}$. $\mathrm{C} 4 \mathrm{AF}$ presents a great impedance to sulphate attack when compared with calcium aluminate hydrate (Saleh, 2008).

\subsection{Chloride}

Chloride attack is one of the primary causes of steel corrosion in RC structures. The main source of $\left(\mathrm{Cl}^{-}\right)$ions is de-icing salts or seawater (Mohammed et al., 2003). Concrete components and in some cases the additives can aid in the entry of chloride into the concrete. These ions penetrate the concrete by a network of fine pores and cracks, which leads to the creation of an oxide film over the steel reinforcement, thus accelerating the corrosion reaction and deterioration of the concrete (Skoglund et al., 2008).

\section{CORROSION EVALUATION}

Corrosion detection or monitoring is the application of continuous evaluation to determine the corrosion level in an element subjected to the harmful environment through the use of "probes" that are put in the process stream and that are repeatedly subject to a state of process flow. According to the work done by (Sadeghi et al., 2019), the following are the popular methods utilized for estimation of corrosion:

\subsection{Corrosion coupons}

The use of this method indicates that corrosion is uncomplicated. it is the oldest method for evaluating corrosion detection in the factory throughout the analysis of weight detriment of coupons.

\subsection{Electrical resistance (ER)}

ER is a commonly used method for assessing metal loss occurring within the instrument. The ER technology measures the influences of the electrochemical and the mechanical components of corrosion, for example, erosion or cavitation.

\subsection{Linear polarization resistance (LPR)}

The polarization stability technology has been used extensively to quickly identify the corrosion disorder and initiate the recovery function, thus prolongation the life of the machine and decrease non-programmed downtime.

\subsection{Inductive resistance (IR) probes}

Inductive resistance probes have a greater resemblance to electrical resistance (ER), but present special sensitivity. The mass variance is detected in the recorder component by evaluating variations in the tenacity of the analogue coil in 
the instrument. For the lifetime of a particular sensor element, these probes will attempt to display a difference in the rate of corrosion that is much faster than the equivalent ER version.

\subsection{Electrochemical impedance spectroscopy (EIS)}

EIS has been utilized extensively to examine the corrosion issue for a long time and has been proven to be a robust and reliable method for determining the corrosion amount. But for the possibility of achieving charge transport continuity or polarity impedance proportional to the corrosion amount at the monitored intersection, the EIS must therefore be illustrated utilizing the interface model. Hz.

\subsection{Harmonic analysis for corrosion monitoring}

By using this new method, it is possible to obtain fast and direct results for the corrosion rate as it just needs a lowfrequency domain. The harmonic analysis is performed through transmitting the $\mathrm{AC}$ voltage at a single frequency and recording the corresponding $\mathrm{AC}$ intensity, while simultaneously recording the two higher harmonics.

\subsection{Electrochemical noise (EN)}

Electrochemical Noise is a non-obstructive method for corrosion estimation which is very impressive, such as the corrosion of aeroplanes. The fluctuation of the probability or operation of a metal erosion sample is a commendable and easily perceptible event, and the appreciation of electrochemical noise as a corrosion instrument is regularly progressing.

\subsection{Zero resistance ammeter (ZRA)}

ZRA is an electrochemical technique that accessed utilizing potentiostat. The potentiostat is an electronic instrument that adjusts the voltage variation between the control electrodes and the trial one.

\subsection{Chemical analyses}

Different types of chemical analyses can provide valuable data in a corrosion control system. The determination of the $\mathrm{pH}$, conduction, soluble metal, oxygen, water alkalinity, aggregation of suspended particles, prohibition concentrations, and scaling shows the complete reduction in this region. Some of these actions result in making on-line with appropriate sensors.

\section{CORROSION CONTROL TECHNIQUES}

Because of the growing need for a longer service life of the infrastructure and the high cost of its construction and maintenance, maintenance of concrete frameworks has become critical. Some commonly utilized corrosion control techniques are summarized as follows:

\subsection{Corrosion inhibitors}

\subsubsection{Anodic inhibitors}

Calcium nitrate is the common widely utilized anodic inhibitor is. It is proportional to the flow of concrete at the worksite as there is no negative influence on the quality of the concrete if it is in a hardened or fresh state. Some other materials like sodium nitrate and potassium nitrate can be utilized as anodic inhibitors because of their great effectiveness in corrosion resistance, but they are not utilized in the case of alkaline accumulations as they appear to interact with the cement and result in a significant deterioration in the concrete (Yang et al., 2015).

\subsubsection{Cathodic inhibitor}

Cathodic inhibitors decrease the corrosion by slowing the rate of the reduction reaction of the electrochemical corrosion cell. This occurs through blocking the cathodic sites by means of sedimentation. Cathodic inhibitors are efficient when they slow the cathodic reaction. Corrosion rates could be decreased by utilizing oxygen scavengers (e.g. sulfite and bisulfite ions) that interact with the dissolved oxygen to form sulfate.

\subsection{Utilizing alternative reinforcement}

In order to reduce rebar corrosion in concrete, an alternative is to utilize reinforcement produced from a corrosion-resistant substance like stainless steel or fibre reinforced plastic.

\subsubsection{Stainless steel (SS) rebar}

SS has proven to be an efficient substitutional to steel bars in preventing corrosion in reinforced concrete structures, but its cost will be higher. Since the cost of SS is slightly higher than normal steel, normal steel is coated with SS with thickness ranging between 1 and $2 \mathrm{~mm}$ to get the same function. It is not recommended to utilize SS together with non-stainless or un-coated SS as this might lead to a quick corrosion of SS rebar (Prachasaree et al., 2015). 


\subsubsection{Fibre-reinforced plastic rebar}

Fibre-reinforced plastic is a composite material consisting of a polymer matrix and a fibrous phase. These fibres have high impedance towards corrosion, in addition to lightweight and high tensile strength.

\subsection{Steel coating}

Corrosion-resistant coatings conserve the steel bars against degradation because of moisture, oxidation, or exposure to a diversity of environments. They should be highly sticky. Coatings allow for additional protection of metal surfaces and perform as a barrier to prevent contact between chemical compounds or corrosive materials (Cicek, 2017).

\subsection{Utilization of superplasticizers (SPs)}

Superplasticizer decreases water amount in the high range. SPs has the ability to decrease the need for water up to 30 per cent without influencing the workability. Alsadey (2015) and Collepardi et al. (1990) concluded the significance of SPs and displayed the characteristics of concrete related to permeability, strength progress, pore structure, microstructure and carbonization. The use of superplasticizers decreases the concrete porosity and permeability; Thus, it can decrease the entry of corrosive agents.

\subsection{Use of pozzolans or admixture}

Admixtures like fly ash, rice husk, silica fume, chemical admixtures, metakaolin, slag, alccofine etc. can be used as a fractional alternative to cement in order to enhance the characteristics of concrete, and further reduce the utilization of raw materials. Pozzolanic reactions are slow at first, so the hydration temperature and the strength progress will be slow as well. Steel passivity in RC is decreased because of the decrease in $\mathrm{Ca}(\mathrm{OH})_{2}$ due to pozzolanic reaction, thus an additional secondary cementing substance is formed, this leads to the filling of the concrete pores, making it denser and thus giving greater impedance to the corrosion of steel rebar (Dinakar, 2007).

\subsection{Adequate concrete cover}

The concrete cover depth is the main agent that inhibits corrosion of the steel built into the reinforcement. The practical perspective can be visualized during construction to agree on the final depth of the covers, $24 \mathrm{~mm}$ large concrete cover evaluated at 100 years from the beginning of steel bars corrosion (Zongjin, 2011).

\section{CONCLUSIONS}

A comprehensive review of the corrosion problems in reinforced concrete structures including the causes, mechanisms, impacts, monitoring and prevention are studied. Corrosion of rebar in concrete is the main issue and must be taken into account when designing concrete structures that are subject to aggressive environments.

\section{CONFLICT OF INTEREST STATEMENT}

The author(s) declare that there is no conflict of interest.

\section{REFERENCES}

[1] Alsadey, S. (2015). Effect of superplasticizer on fresh and hardened properties of concrete. Journal of Agricultural Science and Engineering, 1(2), 70-74.

[2] Alonso, C., Andrade, C., Rodriguez, J., \& Diez, J. M. (1998). Factors controlling cracking of concrete affected by reinforcement corrosion. Materials and structures, 31(7), 435-441.

[3] Cicek, V. (2017). Corrosion Engineering and Cathodic Protection Handbook: With Extensive Question and Answer Section. John Wiley \& Sons.

[4] Collepardi, M., Fratesi, R., Moriconi, G., \& Biagini, S. (1990). The use of superplasticizers as steel corrosion reducers in reinforced concrete. Admixtures for concrete. Improvement of properties, 269-278. http://worldcat.org/isbn/0412374102

[5] Dinakar, P., Babu, K. G., \& Santhanam, M. (2007). Corrosion behaviour of blended cements in low and medium strength concretes. Cement and Concrete Composites, 29(2), 136-145.

https://doi.org/10.1016/j.cemconcomp.2006.10.005

[6] Fernandez, I., Bairán, J. M., \& Marí, A. R. (2015). Corrosion effects on the mechanical properties of reinforcing steel bars. Fatigue and $\sigma-\varepsilon$ behavior. Construction and Building Materials, 101, 772-783. https://doi.org/10.1016/j.conbuildmat.2015.10.139

[7] Imam, A., Mishra, S., \& Bind, Y. K. (2018). Review study towards corrosion mechanism and its impact on the durability of concrete structures. AIMS Materials Science, 5(2), 276-300. https://doi.org/10.3934/matersci.2018.2.276

[8] Isgor, O. B., \& Razaqpur, A. G. (2006). Modelling steel corrosion in concrete structures. Materials and Structures, 39(3), 291-302.

[9] Mohammed, T. U., Otsuki, N., \& Hamada, H. (2003). Corrosion of steel bars in cracked concrete under marine environment. Journal of materials in civil engineering, 15(5), 460-469. 
https://doi.org/10.1061/(ASCE)08991561(2003)15:5(460)

[10] Neville AM (2005). Properties of concrete. Pearson. Prentice Hall, 255- 262.

[11] Ormellese, M., Berra, M., Bolzoni, F. A. B. I. O., \& Pastore, T. (2006). Corrosion inhibitors for chlorides induced corrosion in reinforced concrete structures. Cement and concrete research, 36(3), 536-547. https://doi.org/10.1016/j.cemconres.2005.11.007

[12] Prachasaree, W., Piriyakootorn, S., Sangsrijun, A., \& Limkatanyu, S. (2015). Behavior and Performance of GFRP Reinforced Concrete Columns with Various Types of Stirrups. International Journal of Polymer Science, vol. 2015, 1-9. https://doi.org/10.1155/2015/237231

[13] Quraishi, M. A., Kumar, V., Abhilash, P. P., \& Singh, B. N. (2011). Calcium stearate: A green corrosion inhibitor for steel in concrete environment. J. Mater. Environ. Sci, 2(4), 365-372.

[14] Quraishi, M. A., Nayak, D. K., Kumar, R., \& Kumar, V. (2017). Corrosion of reinforced steel in concrete and its control: An overview. Journal of Steel Structures and Construction, 3(1), 2-6. https://doi.org/10.4172/2472-0437.1000124

[15] Sadeghi, K., Musa, M. K., \& Nassrullah, H. M. (2019). Corrosion problems in RC structures: An overview of causes, mechanism, effects, controls and evaluation. Academic Research International, 10(2), 15-28.

[16] Saleh, A. (2008). Chloride Induced Corrosion and Sulphate Attack-A Literature Review on Concrete Durability. The $3^{\text {rd }}$ ACF International Conference$A C F / V C A$, Elkem Materials South East Asia, Singapore, 1028-1040.

[17] Skoglund, P., Silfwerbrand, J., Holmgren, J., \& Trägårdh, J. (2008). Chloride redistribution and reinforcement corrosion in the interfacial region between substrate and repair concrete-a laboratory study. Materials and structures, 41(6), 1001-1014. http://doi.org/10.1617/s11527-007-9301-6

[18] Yang Yu, Xin Shi, \& Ping Yang. (2015). Simulation on the steel galvanic corrosion and acoustic emission. Sixth International Conference on Electronics and Information Engineering, 9794, p. 97942E. https://doi.org/10.1117/12.2202387

[19] Zhou, J. (2011). A study of acoustic emission technique for concrete damage detection. Master Dissertation, Michigan Technological University. Digital Commons @ Michigan Tech. https://doi.org/10.37099/mtu.dc.etds/726 